В качестве примера взяты кроссоверыJaguarE-PACE, BMWX3, AudiQ4, которые являются прямыми конкурентами друг другу по техническим характеристикам и портретам целевой аудитории. У всех брендов в 2019 году наибольшая доля принадлежит интернет-размещениям, ввиду их сравнительно низкой стоимости относительно размещений на ТВ. Форматы наружной рекламы теряют свою популярность с каждым годом, благодаря тренду на цифровизацию. Бренды все больше отказываются от статичных размещений в пользу динамических креативов. Акцент на интернет-размещения позволяет более точно отследить путь потребителя и выявить интересы целевой аудитории благодаря механизмам таргетинга.

Заключение. Сегодня наблюдается смещение акцентов со статичного контента в пользу динамического. Наружная реклама становится анимированной и размещается на медиа-фасадах, привлекая больше внимания аудитории.Социальные сети также насыщаются видеоконтентом. Брендам важно следить за постоянством его обновления, добавляя интеграции с блоггерами, обзоры и тест-драйвов других СМИ. Важно работать с поисковойоптимизацияей страниц с видео (верно составлять описание, заголовки, проставлять метатеги), а также структурировать свой канал, составляя плейлисты по отдельным темам.Призывы к действию, ссылки на сайт и элементы конверсии в видеороликах или описаниях также важно верно формулировать, чтобы продвигать видеоконтент.

Автомобильные бренды премиум-класса становятся более активными в вопросах взаимодействия со своей аудиторией, проводя прямые эфиры в соцсетях, проводя розыгрыши и конкурсы, внедряя локальных амбассадоров как официальных представителей бренда на местах. Эти люди разделяют ценности бренда и способны лучше, чем знаменитости, блоггеры и другие инфлюенсеры влиять на свое окружение.

$$
* * *
$$

1. Алашкин П. Все о рекламе и продвижении в Интернете - М.: Альпина Бизнес Букс, 2018, с. 35

2. Joe Pulizzi, Robert Rose. Killing Marketing: How Innovative Businesses Are Turning Marketing Cost into Profit, 2019, p. 101

3. Андросова Н.О. Интернет-маркетинг на 100\% - Спб.: Изд. Питер, 2016., с.49

4. Данченок Л. «Маркетинг в социальных медиа. Интернет-маркетинговые коммуникации», 2017, с. 111

5. Исаева Е.В. Базовые инструменты интернет-маркетинга для промышленных компаний // Вестник ОмГУ. Серия: Экономика. - 2016, с.71

6. Стратегия бренда Jaguar с 2020 года: утв. 01.10.2019 - Бирмингем, 2019. 130 с.

7. Анализ коммуникационной активности конкурентов Jaguar с 2014 по 2019 год. Утв: 02.09.2020 Москва, 2020. 73 стр.

Лочан С.А., Безпалов В.В., Федюнин Д.В.

\title{
Методы и инструменты управления корпоративным PR региональной коммуникационной группы
}

Российский экономический университет им. Г.В. Плеханова

(Россия, Москва)

doi $10.18411 / g q-31-03-2021-45$

idsp sciencerussia-31-03-2021-45

\section{Аннотация}

Одним из приоритетных направлений деятельности специалистов по связям с общественностью является, собственно, управление этими связями общественности с субъектом PR, создание позитивного и вызывающего интерес имиджа для той или иной региональной организации, на которую он работает. Практически все нынешние организации, правительственные организации, социальные структуры, так или иначе, осуществляют свою деятельность, находясь в постоянном взаимодействии, как с внутренней, так и с внешней средой. Непрерывно находясь в этой сложной системе 
взаимодействий, эти связи могут оказать существенное влияние на деятельность региональной организации и принимаемые ею решения. Фактически, управление этими взаимодействиями становится одной из основополагающих функций региональной организации. Работа со связями с общественностью, в зависимости от поставленных на текущий момент целей способно решить различные задачи, но в фокусе неизменно будет оставаться создание эффективного корпоративного PR региональной организации, создание эффективного имиджа организации и дальнейшее его совершенствование, на основе чего формируется доверительное отношение к организации и её репутации.

Ключевые слова: Корпоративный PR, коммуникационная группа, информационные технологии, цифровая экономика, комплексный подход

\section{Abstract}

One of the priority activities of public relations specialists is, in fact, managing these public relations with the subject of $\mathrm{PR}$, creating a positive and interesting image for a particular regional organization for which he works. Almost all current organizations, government organizations, social structures, in one way or another, carry out their activities, being in constant interaction, both with the internal and external environment. Constantly being in this complex system of interactions, these connections can have a significant impact on the activities of a regional organization and its decisions. In fact, the management of these interactions becomes one of the fundamental functions of a regional organization. Working with public relations, depending on the goals set at the moment, can solve various tasks, but the focus will always remain on creating an effective corporate PR of a regional organization, creating an effective image of the organization and further improving it, on the basis of which a trusting attitude to the organization and its reputation is formed.

Keywords: Corporate PR, communication group, information technologies, digital economy, integrated approach

Стремительные темпы роста информационных технологий дают возможность значительно увеличить перечень услуг, которые могут предоставить нынешние коммуникационные агентства. И хотя суммарно рынок рекламы впервые за долгое время снизился на 8\% в сравнении периода январь-сентябрь 2019 и январь-сентябрь 2020 [1], изменяющиеся функции и усилившуюся роль средств массовой информации в разработке стратегии компании-клиента, а также перспектива общения напрямую с целевыми аудиториями в серьёзной мере изменили технологии воздействия на общественное мнение.

На текущий момент большая часть экспертов более или менее одинаково интерпретируют и функции, и роль, которую занимают в медиа сфере коммуникационные агентства. Большинство из них сходится в том, что приоритетными являются не единичные коммуникационные услуги, но функции стратегического планирования всей коммуникации клиента.

Благодаря такому комплексному подходу, для клиента открываются возможности для налаживания стабильного и эффективного контакта с различными целевыми аудиториями. Помимо этого, агентство выполняет поставленные клиентом цели и задачи, делая таким образом коммуникационный потенциал более успешным и эффективным по всем интересующим данного клиента направлениям. Можно с уверенностью сказать, что коммуникационное агентство - это концентрация в рамках одной компании экспертов в большинстве ключевых аспектов деятельности в медиа сфере, способных предоставить партнеру - заказчику решения по всем видам коммуникаций. Немаловажной составляющей позиционирования является внутренний PR организации, помноженный на управление персоналом, в ряде научных трудов и регулярно встречающийся в профессиональном жаргоне HR - брендинг. 
Одним из таких инструментов, а точнее их комплексом является управление корпоративным PR. В его рамках все мероприятия, связанные с позиционированием, централизуются, благодаря чему появляется возможность стратегического планирования и оперативного управления имиджевыми процессами. Благодаря управлению корпоративным PR, к примеру, можно выстроить стратегию того, как, где и в какое время будут выступать ключевые представители компании, в каком формате будет их выступление, будь то различные мастер-классы, лекции, презентации, экспертные комментарии для СМИ и так далее. Помимо этого, возможно обучение потенциальных клиентов и это в свою очередь тоже может зарекомендовать организацию как место, где работают высококвалифицированные специалисты. Как следствие, в рамках агентств, так или иначе, ведущими экспертами компании образуется база «профессионального обучающего контента», предоставляющего доступ к наиболее полезным и актуальным кейсам, которые могут быть полезны остальным сотрудникам организации с целью поддержания уровня актуальности знания происходящих на рынке процессов и повышения квалификации.

Основными факторами, существенно повлиявшими на развитие индустрии коммуникационных услуг, является непрерывное за последние годы рост объёма сегмента «Интернет» [2] и роста в рамках сегмента различных «новых медиа» и социальных сетей, а также развития интерактивных и digital коммуникаций. Благодаря им рынок, из разряда творческой индустрии, приобрел статус индустрии высоких технологий, и уже сейчас мало какое агентство решается на предоставление пакета услуг, в котором не фигурирует digital - сегмент.

В цифровую эпоху немалым преимуществом обладают компании, вложившиеся в создание эффективных горизонтальных коммуникаций. Данные коммуникации подходят для групп компаний и представляют собой единое, централизованное управление брендом всей компании в целом. Горизонтальные коммуникации также предполагают ориентирование коллектива на конкуренцию среди однотипных, представленных на рынке товаров и/или услуг, что в свою очередь приводит к развитию взаимоотношений, как с клиентом, так и совсем коммерческим и некоммерческим секторами рынка коммуникаций.

Корпоративные потребительские рынки перенасыщены технологиями продвижения. Технологический скачок в сфере передачи информации осуществил переворот в маркетинге и послужил началом новой электронной эпохи в коммуникациях. На протяжении двадцатого века неоспоримыми лидерами в предоставлении информации о конкурентных преимуществах товаров условного заказчика были технологии брендинга. Однако век двадцать первый диктует новые условия. Так, все больше становящиеся искушенными в сфере коммуникации потребители уже в меньшей степени доверяют брендинговым технологиям, в частности, рекламной деятельности. Наибольшее доверие сейчас вызывают технологии, при помощи которых организация выглядит более открытой, социально ответственной, ориентированной на клиента и создания для него благоприятной среды и высокой степенью информационной доступности. Говоря об имидже компании, сейчас он воспринимается как компонент продвижения компании, поддерживающий внимание и интерес к ней, задающий определенный тон дальнейшей коммуникации и формирующий оценочно-мотивационное отношение к деятельности агентства.

Прямыми инструментами формирования имиджа организации принято считать event-технологии [3], внутрикорпоративную культуру, имиджевую рекламу, публикации в СМИ, а также знаковое месторасположение компании [4] Объектами исследования корпоративной культуры были выбраны сайты рекламных агентств, публикации от имени сотрудников агентств, в которых они рассказывают об агентстве, и другие тексты, которые можно будет отнести к элементам управления корпоративным брендом. 
Американское креативное рекламное агентство Wieden+Kennedy [5] использует в качестве собственного неформального слогана “Just drive me, dude". Основой корпоративной культуры данного агентства служит желание быть неповторимой индивидуальностью, не пытающейся копировать других. Это, в свою очередь, является основой деятельности всей организации, как и ее рекламной стратегии - квинтэссенции креатива и неповторимости рекламного сообщения. По мнению представителей агентства, особой эффективностью отличается реклама не шаблонного, а развлекательного характера. Нью-йоркское агентство Droga5 [6] воспринимает корпоративную миссию как помощь в создании и поддержании высокого уровня репутации влиятельнейших компаний и брендов XXI века: “цель каждого клиента эффективность, и мы стремимся достичь этого с помощью кампаний, которые влияют на культуру”. Влияние на культуру является фактором изменения результатов бизнеса.

Имеющее офисы Москве, Лондоне и Барселоне, агентство HungryBoys [7] идентифицирует себя как "агентство с digital-сердцем, влюбленным в хорошую рекламу”. Заявленная миссия компании в России - сделать востребованной российскую творческую мысль в мире. "Мы не боимся смелых решений, которые на первый взгляд кажутся невыполнимыми и даже утопичными. Мы хотим, чтобы российская рекламная индустрия росла и развивалась благодаря молодым талантливым людям, которых немало в нашей стране. В данном направлении мы видим акцент агентства на развитие молодежи, как воплотителей смелых, новых решений”. «McCann Moscow World Group» [8] определяет свою стратегию так: “наш стратегический подход, основанный на нашей основополагающей и прочной философии правды, подтвержденной нашей истиной, базируется на нашем убеждении в том, что «истины бренда» могут служить катализатором для создания мощных идей, которые преуспевают, потому что они помогают брендам играть значимую роль в жизни людей. Благодаря нашим интегрированным мировым возможностям, «McCann» помогает нашим клиентам стимулировать рост своих брендов по медиа-

Каждое агентство в собственной деятельности стремится выработать уникальный, присущий только ей, подчерк. С одной стороны, это обуславливается спецификой клиентского заказа и поставленных им целями и задачами с другой личными вкусами, собственными предпочтениями и никогда не повторяющимся профессиональным опытом занятых на тех или иных проектах сотрудников. Все сотрудники агентства, без исключения, являются носителями идеологии агентства, его корпоративной культуры. Что обуславливает открытость информации на сайтах агентств, как о самой компании, так и ее кейсов. Через своих сотрудников, организация транслирует свои философию, мировоззрение и ценности. Проделанная, к слову, компанией работа сама по себе является существенной отсылкой к её внутреннему креативному миру. Так в коммуникации московской компании «BigJack» [9] активно используются образы героев сказок или известных киногероев. Сюжетные линии отличаются элементами квеста и интерактива. Продукция компании несет в себе яркие характерные цветовые решения, под каждый проект разрабатывается индивидуальная палитра.

«TWIGA - крупнейшая независимая региональная коммуникационная группа в России и СНГ, объединяющая профессиональные агентства, специализирующиеся на ключевых рекламных дисциплинах. И в каждой из них у компании имеются конкуренты - довольно серьёзные игроки на рынке.

В первую очередь, что становится объектом внимания, это многообразие конкурентов группы компаний TWIGA. Объясняется это присутствием подконтрольных группе агентств, в той или иной степени, в рамках пяти ключевых дисциплин рынка коммуникационных услуг. Такое многообразие также говорит об обширных возможностях группы агентств для реализации комплексных, кроссплатформенных действий в рамках реализации выбранных стратегий управления 
брендом клиентов, но также это говорит и о важности разработки более обширной стратегии по управлению собственным корпоративным PR, охватывающей все подконтрольные агентства, иначе не исключены потери в эффективности деятельности коммуникационной группы на том или ином направлении. Компания располагает клиентской базой.

Логотипом компании, выступает само название компании, обозначающее TWIGA Communication Group. Иногда в организации используют логознак, изображающий жирафа.

Компания была одной из первых кто осознал важность современных технологий, поэтому уже в 2014 году сегмент Digital был выделен в новую, отдельную структуру, что является немаловажным свидетельством того, что в условиях современности ни одно агентство не способно предоставить адекватные действительности и требованиям клиента услуги без использования современных технологий, в особенности, СМИ, включающих в себя, разумеется новые медиа. Обособление агентством Digital-сегмента позволило обеспечить коммуникационной группе конкурентное преимущество в виде усиления междисциплинарных связей, раскрыть потенциал для нахождения новых решений, а также приобретение в собственный арсенал инструментов и сервисов, для которых требуется глубокое понимание цифровых технологий. Это, в свою очередь, свидетельствует о дальновидности компании, поскольку на 2020 год именно с digital-направлением в большей степени связаны заказы от клиентов. Объединенные в рамках этого сегмента знания позволили изменить отношение к digital-направлению, превратив его не просто в набор инструментов, но в аналитический центр, позволяющий более детально изучать потребителя, устанавливать с ним прямой контакт и создавать именно то, что ему нужно.

Помимо успешного предвидения положения дел на рынке коммуникационных услуг, «аспект дальновидения» компании распространяется также на частые публикации организации в СМИ, представляющие как экспертные мнения по различным аспектам рынка коммуникационных услуг.

Важными инструментами корпоративного PR организации являются ее ноу- хау проекты, такие как TWIGA Bar, TWIGA Academy, TWIGA New Agency Pitch, a также TWIGASHOP.

Помимо всего прочего, TWIGA CG принимает активное участие как в организации, так и в реализации множества социальных проектов. Так, например, внутрикорпоративное агентство TWIGA Touch является партнером программы «Социально активные медиа», а также находится в сотрудничестве с «Российским фондом помощи тяжелобольным детям» (Русфонд), ПСО «Лиза Алерт», благотворительным общественным фондом «Детские сердца», образовательным фондом «Айб», благотворительным фондом «Добросердие», благотворительным фондом и образовательным центром «Большая Перемена».

Важность анализа внешней среды для успешной реализации корпоративной PR стратегии обуславливается направленностью данного вида коммуникации не только на внутренние аудитории компании, но и на внешние аудитории, а залогом формирования эффективной стратегии управления корпоративным PR является как раз понимание того, как внешняя среда и какие ее конкретные факторы способны повлиять на деятельность компании в данной области.

Одна из специфик работы с имиджем коммуникационной группы заключается в том, что самый главный ресурс организации - это ее эксперты, предоставляющие полный спектр услуг в сферах рекламы, маркетинга, PR, диджитал и креатива. Быть экспертом - значит будь в курсе практически всех происходящих в твоей сфере компетенции процессов и влияющих на индустрию факторов внешней среды. 
Анализируя факторы внешней среды, целесообразно говорить о том, что за счет образовавшегося снижения объёмов традиционной рекламы и усиления значимости digital-коммуникаций возникает угроза прихода в образовавшуюся нишу новых конкурентов, а также усиления позиции старых. В таком случае, агентство может снизить подобные риски путем увеличения своей доли рынка и развития бренда, что требует большего внимания к развитию маркетинга и технологиям управления корпоративным PR. Помимо этого, ни на минуту нельзя забывать об угрозе разрыва отношений с клиентом, возможной в результате неэффективной деятельности агентства, что поведет за собой снижение его привлекательности в глазах потребителей, а следовательно и снижением его прибыльности и потери доверия в среде клиентов.

В отношении рынка рекламных услуг данный кризис примечателен тем, что, в сравнении с предыдущими кризисами, снижение компаниями-клиентами затрат на собственное продвижение не так существенно сказывается на благосостоянии коммуникационных агентств. В первую очередь это связано с тем, что коммуникационная деятельность за прошедшие годы приобрела статус высокотехнологичной. Раньше клиент практически сразу вычеркивал статью расходов на рекламу из планов на бюджет. Сейчас же, ввиду усложнения технологий коммуникации и каналов выхода на потенциального покупателя, многие компании возможно и сократили свои расходы на традиционные СМИ, однако были вынуждены осваивать для себя технологии новых СМИ и медиа, чтобы подстроиться под нынешнюю реальность. Основываясь на наиболее значимых из выявленных при помощи PEST анализа факторов, автором данной работы были разработаны пути возможного совершенствования управлением корпоративным PR TWIGA CG.

На 2020 год руководством компании были поставлены следующие цели и задачи. Главная цель: повышение “знания" об экспертизе каждой дисциплины, в рамках которой действуют агентства группы. Общее понятие «знание» специалистами отдела по работе со связями с общественностью TWIGA CG было разбито на четыре подпункта:

1) повышение уровня знания потенциальных клиентов о предоставляемых коммуникационной группой услугах,

2) повышение уровня известности ключевых экспертов компании в разных сферах ее деятельности

3) предоставление своим сотрудникам возможность непрерывно повышать свою квалификацию,

4) создание для сотрудников благоприятных условий для их работы.

Реализация намеченных целей, в свою очередь, были разбита на конкретные задачи и подзадачи:

1. Медиа Индекс

- Увеличить главный показатель Media Relations - Медиа Индекс не менее 950 в $2020(+200)$

Соответственно, чем больше показатель данного индекса, тем более ярко и позитивно представлена коммуникационная группа в СМИ

- Обеспечить рост подписчиков на приоритетных платформах социальных сетей - Facebook и Instagram (+500 подписчиков на обеих платформах)

Для этого требуется:

- минимум 1 инфоповод в месяц

- участие экспертов группы в индустриальных мероприятиях (до 10 мероприятий в год)

- публикации в профильных и деловых СМИ (20)

2. $\quad$ HR брендинг (он же внутренний PR) 
- Проведение систематических мероприятий для сотрудников

- Проведение ежеквартальных анонимных опросов среди сотрудников удовлетворенности сервисами коммуникационной группы

- Проведение креативных сессий, тренингов.

- Обновление и улучшение фирменного стиля TWIGA CG

3. Развивать и поддерживать благоприятные отношения с клиентами

- Систематические мероприятия: ноу хау организации специализированные бизнес завтраки с приглашенными гостями TWIGA Bar, организация и планирование вечеринок и совместное участие в конференциях

- Сбор и анализ данных по клиентам. Практически всех новых посетителей организованных мероприятий следует считать потенциальными клиентами

- Проработка системного наполнения для программы лояльности клиентов

4. Brand Health Track

- TQC: системное получение обратной связи от клиентов 1 эшелона, увеличение \% откликнувшихся клиентов до $80 \%$ (проводить ежеквартально);

- проведение конкурентного анализа раз в полугодие

Первое полугодие 2020 года запомнится всему миру на долгие годы, а его последствия для бизнеса в целом можно охарактеризовать, как «глобальный стресс тест» на устойчивость, и умение подстроиться под текущие нужды.

Фирменный стиль компании был подвергнут изменениям, с целью большего соответствия корпоративному коду. Фирменный цвет организации - темнофиолетовый, символ ума, прозорливости и мудрости. Тексты теперь пишутся в более мягком для восприятия, но выдерживающим официальный структурированный тон формат Arial.

Несмотря на то, что коммуникационная группа TWIGA показывает по промежуточным итогам хорошие показатели, особенно в статистике посещения сайта, и остается в ТОП 10 Национального рейтинга коммуникационных компаний, последствия глобальной пандемии существенно сказались на рейтинге Медиа Индекса организации в сравнении с ее ключевыми конкурентами. Проанализировав внешнюю среду и деятельность компании в рамках управления корпоративным PR, авторами предлагаются следующие рекомендации:

1. Продолжать основное векторное направление компании на повышение уровня знаний об экспертизе и уровне профессионализма сотрудников компании по ключевым дисциплинам. Активно дифференцировать профессионализм находящихся в рамках группы агентств.

2. Исходить из той точки зрения, что глобальная ситуация на рынке не изменится в ближайшие 1-2 года, даже с последовательным введением вакцинации от коронавируса в странах, представляющих интерес для организации

3. Уделить большее внимание онлайн - мероприятиям и конференциям, активно продвигать на них своих экспертов. Постоянно следить за появлением новых мероприятий, составом их участников и рейтингом мероприятий на сайтах АКАР, Тэглайн, Sostav.ru.

4. В столь непростые времена особенно важны внутренние мероприятия, не стоит следовать примеру многих других предприятий и сокращать на них издержки, но стоит их адаптировать под текущие реалии, и по возможности, сосредоточить их проведение в онлайн режиме. 
5. Интенсифицировать отношения с отраслевыми организациями, такие как АКАР, РАСО, АМР, РАМУ и другие. Усилить участие в их мероприятиях, предлагать совместные проекты, а также увеличить количество публикаций на их ресурсах.

6. Сосредоточить усилия на повышение показателя Медиа Индекса посредством: участия в жизни отраслевых организаций, активного продвижения экспертов группы, более тесного сотрудничества с профильными СМИ (экспертные мнения, актуальная аналитика, и прочее)

7. Детальнее проанализировать ситуацию с приоритетными социальными сетями и рассмотреть возможности по увеличению контента. Так же рассмотреть возможности создания страничек в других социальных сетях.

$$
\text { *** }
$$

1. Объем рекламы в средствах ее распространения в январе-сентябре 2120 года. [Электронный pecypc]. https://www.akarussia.ru/knowledge/market_size/id9399 (Дата обращения 23.01.21)

2. Объем рекламы в средствах ее распространения в 2119 году. [Электронный ресурс]. -URL: https://www.akarussia.ru/knowledge/market_size/id9112 (Дата обращения 24.01.21)

3. Малышко Е.П. Event-менеджмент как способ продвижение рекламного агентства // Творчество молодых: дизайн, реклама. Сборник трудов XVI национальной научно-практической конференции студентов и аспирантов. Изд-во: Омский государственный технический университет (Омск)

4. Петушкова Е.В., Спиридонова А.И. Геолокация рекламного агентства как инструмент формирования его габитарного имиджа // Неделя молодежной науки. Сборник научной конференции. С. 382-386

5. Официальный сайт агентства Wieden+Kennedy. [Электронный ресурc]. -URL: http://www. wk.com (Дата обращения 21.01.21)

6. Официальный сайт агентства Droga5. [Электронный ресурc]. -URL: http://www.droga5.com(Дата обращения 21.01.21)

7. Официальный сайт агентства HungryBoys. [Электронный pecypc]. -URL: https://hungryboys.ru (Дата обращения 21.01.21)

8. Официальный сайт агентства McCann. [Электронный ресурc]. -URL: http://www.mccann.ru (Дата обращения 21.01.21)

9. Официальный сайт агентства BigJack. [Электронный ресурc]. -URL: http://www.BigJack24.ru(Дата обращения 22.01.21)

\section{Нафикова Л.Ш. Методы оценки устойчивого развития}

ООО «Башнефть-рознища» (Россия, Уфа)

doi $10.18411 / g q-31-03-2021-46$

idsp sciencerussia-31-03-2021-46

\section{Аннотация}

Концепция устойчивого развития приобрела немалую популярность в научных и практических кругах в последнее время. Во многом, этому способствовала современная ситуация поиска более эффективной модели управления социально-экономическими системами. Экономический кризис, рост активности государства в экономике, влияние региональных и межгосударственных союзов на перераспределение экономических сил повлекло рост неопределенности. Это в свою очередь, усилилось наличием нерешенных вопросов теоретического толка: ни одна теория развития экономических систем на современном этапе не может в полном объеме объяснить всю совокупность явлений, происходящих в экономике мира.

Ключевые слова: устойчивое развитие, концепция, методы устойчивого развития

Современная концепция устойчивого развития не приобрела законченный вид. Научный и практический интерес к устойчивому развитию социально-экономических 